\title{
Individualization of Training Using the Resources of International Digital Platforms
}

\author{
A.I. Popov ${ }^{1}$, and R.V. Fedorenko ${ }^{2, *}$ \\ *Corresponding author: fedorenko083@yandex.ru. \\ ${ }^{1}$ Tambov State Technical University, Tambov, Russia \\ ${ }^{2}$ Samara State University of Economics, Samara, Russia
}

\begin{abstract}
The article is devoted to the definition of psychological and pedagogical conditions and design methods of formation of a creatively thinking specialist using international digital platforms. The following universal abilities making up a specialist's competitiveness are defined: creativity, digital literacy, and psychological stability. The importance of tolerance for international innovation is shown. The state and directions of development of education digitalization are analyzed. Psychological and pedagogical conditions are revealed, and provisions of the concept of training individualization are defined. A set of measures are considered to facilitate the passage of students personal educational trajectory. The experience of organizing individual creative development in the digital space of the Union state is described. The introduction of the developed theoretical and methodological conceptual provisions of training individualization will provide conditions for improving the quality of vocational education and training for the implementation of innovative programs in the framework of international cooperation.
\end{abstract}

Keywords: education digitalization of education, professional creativity, international cooperation, distances learning.

\section{Introduction}

Satisfying the growing needs of individuals and society in competitive education presupposes a dynamic renewal of the education system. Vocational education should not only prepare for the performance of standard labor functions, but also develop the creativity of the individual, motivate her to further self-improvement. Improving the quality of education can be achieved with the active use of the potential of digitalization. The use of digital educational platforms and technologies is caused by the need for flexible updating of the content of training in accordance with the achievements of scientific and technological progress and taking into account the trends of the emerging innovative economy [1]. The digital transformation of a company can be successful only if there are people in the company who can competently carry it out [2]. High competition in the labor market and the need for lifelong education throughout life increase the relevance of the formation of a personal educational path and adaptive management of the process of creative development of the individual.

\section{Problem Statement}

Modern globalization, growth and competitiveness of the national economy, geopolitical and geo-economic factors determine the level of intellectualization of the main factors of production [3]. Globalization of all economic processes and the establishment of the sixth technological order in industry determine new requirements for a competitive specialist: readiness for creative non-standard activities in a competitive environment; the ability to take into account the specifics of economic and legal support of professional activities in the implementation of international innovative projects [4]. Economic reasons that encourage a significant number of people to get a new education in parallel with work, and the need to continuously improve their skills increase the relevance of using the resources of digital educational platforms, especially in online learning [5]. The content of education and the technologies used should take into account both the requirements of specific employers [6] and the individual characteristics of the knowledge of a particular student.

The problem of developing a methodology for individualizing training in vocational education with the optimal use of the resources of international digital platforms requires special attention and a separate scientific research. A deeper study of this problem from new theoretical and methodological positions should be carried out taking into account the contradictions identified on the basis of research and practical experience in higher education:

- the need of the individual for creative self-realization and taking into account individual characteristics, and the limited possibility of the educational environment of one university to ensure the corresponding realization of creative potential and personal educational requests;

- a potentially international sphere of activity in the context of the globalization of the economy and the focus of the educational process at the university on the solution of specific narrowly targeted problems. 


\section{Research Questions}

In the process of psychological and pedagogical research, the main attention was paid to determining the conceptual provisions of the methodology and developing a model for personified learning in the context of digitalization of education. Of interest is the problem of combining competence and activity approaches in distance learning on international educational platforms and overcoming the psychological deformation of students when working in virtual space $[7,8]$. In the context of the development of the personnel component of innovation in work, the mechanisms of creativity development when working in digital space were investigated.

\section{Purpose of the Study}

The aim of the study is to determine the psychological and pedagogical conditions and design a methodology for the formation of a creatively thinking specialist when using international digital platforms. The developed theoretical and methodological conceptual provisions for the individualization of education should provide conditions for improving the quality of vocational education and training for implementation of innovative programs in the framework of international cooperation. The provisions and conclusions of the study can become part of the theoretical basis for improving the professional training of an innovative specialist for creative activities in the digital economy.

\section{Research Methods}

The main methodological approaches used in the design of technologies for individualizing instruction through the use of international educational platforms are competency-based and personality-active. The competency-based approach was implemented through the presentation of the goals and objectives of training in the form of a list of creative competencies of a specialist, determining the ability to realize oneself in the field of international cooperation. The process of creative professional development of a student is considered as personality-related. The development of a personal educational trajectory is the result of the student's educational activity in the digital educational space. To solve the tasks, research methods were used: analysis and synthesis; modeling of pedagogical phenomena; direct and indirect observation of the process of cognitive activity of students in the digital educational space; study and generalization of the experience of digitalization of education.

\section{Findings}

\subsection{Competitive Model}

The development of the digital economy requires appropriate training of specialists who are able to think creatively and maximize their intellectual and creative potential in the implementation of professional activities. At the same time, they must work effectively in the digital space, introducing advanced digital technologies in the production process [9].

The study of the dynamics of the formation of an innovative economy and globalization processes, an analysis of development trends and structural transformation of the labor market made it possible to determine the universal abilities that determine the specialist's competitiveness:

- the creative nature of thinking and the willingness to make innovative decisions in professional activities;

- digital literacy and knowledge of the tools of the digital economy;

- readiness for self-education and self-development, obtaining a new profession and qualification in the digital educational space;

- willingness to work in the face of restrictions and psychological stress.

For effective professional activity in the context of a globalized economy, a specialist needs to have economic and legal competence both at the national level and at the level of countries - potential partners. An important quality of a competitive specialist will be his genuine tolerance for cultural values and psychological characteristics of representatives of a multinational and multiconfessional modern society, included in innovative activities at the supranational level.

The ego-identity formed in childhood and adolescence (low self-sufficiency, lack of willingness to take responsibility, poor creative initiative) and group identity, as well as hypertrophied involvement of some representatives from real processes in virtual space are the constraints on the manifestation of the abilities required by the economy youth.

\subsection{Problems and directions of development of digitalization of education}

The digitalization of education is constrained by objective and subjective reasons. Let us single out a number of problematic issues that impede the optimal use of the possibilities of digitalization of education.

1. Narrow specialization is part of the educational content. The ability to use content and technology. 
2. Advantages of reproductive-oriented development of the educational resource, insufficient creative orientation of the student in the learning process.

3. The lack of sophistication of the legal framework for e-learning and the use of distance learning technologies, legal difficulties in the formation of a personal educational trajectory.

The most popular areas in the field of digital education technologies are:

- the optimal combination of traditional learning (with the direct interaction of the student and teacher) and digital learning;

- creating a system of adaptive management of personal educational trajectory based on digital traces of students, their needs and personal qualities;

- use of resources of international educational platforms for phased acquaintance with national cultural and mechanisms of economic and legal regulation of activities of interest for the development of international cooperation.

\subsection{The concept of individualization of learning when using the resources of international educational platforms}

Digital professional education in modern socio-economic and political conditions should be integrated with traditional and innovative teaching technologies, and based on the psychological and pedagogical characteristics of specific groups of students and the mastered subject area, ensure the rational use of the intellectual and creative potential of students. The key is the understanding of the student as a creative person, the orientation on the development of his integrity and the diversity of individual manifestations, the outstripping development of his creative activity. The main goal of the digital educational process is to increase the level of intellectual activity of the student (to heuristic and creative levels). This will allow the specialist to most fruitfully realize their abilities in professional activities and in the process of creative self-development.

In the process of research, psychological and pedagogical conditions were identified that determine the effectiveness of the formation of readiness for innovative activities in the framework of international cooperation:

- the content of education presented on the used international educational platforms should be aimed at developing creativity and the manifestation of leadership qualities in conditions of psychological stress;

- the training tools are problem situations that reflect the subject and social contexts of activity and are of an interdisciplinary nature;

- educational activities should have an element of competitiveness, aimed at the formation of psychological stability;

- a system for monitoring the digital footprint of students in the context of designing a personal development path is needed;

- the creation of a favorable psychological background of cognitive activity in the digital space is ensured by the alternation of periods of intense intellectual activity and stages of reflection and relaxation.

- a correction of the teacher's thinking is necessary, suggesting a change in his role in the digital educational process from a leader to an equal participant, coordinating the process of creative self-development of students and developing along with them.

The solution to the problem of individualization of learning in the context of digitalization is carried out through a set of measures, including:

- the organization of advanced training in accordance with the educational needs and capabilities of students, the adjustment of the content of training taking into account economic development trends;

- strengthening the spiritual and moral development of students through the expansion of digital elective courses focused on universal values and the development of tolerance; support of informal education in the electronic environment;

- ensuring the availability of technical education for persons with disabilities;

- expansion of economic and legal training of technical specialists;

- accompaniment of the creative development of gifted students through their access to the bases of creative tasks and the organization of interactive work of informal groups in a remote format;

- organization of project training in the framework of interaction with industrial enterprises and research organizations in the digital space; the creation of virtual study groups from students of various forms and courses, the involvement of leading practitioners as experts.

\subsection{Practical implementation}

The globalization of the economy, affecting all aspects of the ongoing economic processes, involves reaching a new level in the field of economic and legal support for the work of joint ventures, support for business entities to enter international markets. In modern political conditions, one of the promising areas for using international educational platforms is the training of specialists for the Union State of the Russian Federation and the Republic of Belarus. The main attention is paid to the formation of economic, legal and digital competencies of specialists. The design of the content of the educational platforms of the universities of the two countries, ensuring the implementation of the components of the personal educational path of specialists in the innovation sphere, involves the following actions.

1. The formation of a set of problem situations in the organization of joint economic and scientific activities. 
2. Creation of digital platforms for the implementation of joint projects in priority areas of the economy. Ensuring both a regime of intensive generation of ideas and development of a program for the implementation of the project, as well as stages of reflection and relaxation.

3. Integration into a single database of all regulatory documents governing the implementation of joint projects or interaction with partner organizations within the Union State. It is necessary to bring the structure of this information as close as possible to use by enterprise managers. For this, a comparative analysis of the documents regulating the same business process in each of the countries of the Union State is carried out, recommendations are prepared for resolving possible contradictions in the legal framework.

4. Development of an information system that allows you to find a potential partner or buyer of products, as well as organizations performing stages of applied research to create new equipment or technologies.

As part of the interaction between universities of the Russian Federation and the Republic of Belarus, approaches have been taken to create an open digital educational environment in the form of a set of international educational platforms.

The organization of personalized training when using the resources of digital educational platforms allowed at a higher level to form competencies that determine the innovative readiness of a specialist:

- knowledge of information and communication technologies;

- free orientation in legal relations and the regulatory framework of the economic processes of the Union State countries; understanding of the need to take into account the characteristics of the economic policies of partners and socio-political processes;

- knowledge of the specifics of the mentality of potential economic partners and the ability to establish trustful and mutually beneficial relations, sociability and tolerance;

- possession of the skills to carry out joint activities at the level of educational and student research, project activities.

\section{Conclusion}

The competitiveness of a specialist and readiness for international cooperation determine his creativity, digital literacy and psychological stability. To prepare specialists for the implementation of international innovative programs, it is necessary to create a system for managing personal educational trajectories and optimal use of the resources of international educational platforms. Learning in the digital space involves the use of problem situations and competitive activities to enhance thinking. The effectiveness of individual learning is enhanced by the alternation of intense cognitive activity and the stages of reflection and relaxation. Using the resources of international educational platforms ensures the passage of a personal educational trajectory and the formation of readiness for international cooperation in the era of globalization.

\section{References}

1. S.D. Starygina, N.K. Nuriev, E.A. Pechenyj, A.A.M. Obadi, Designing smart education systems with digital technology. Educational Technologies and Society, 22(3), 54-66 (2019). [in Rus.].

2. T.O. Tolstykh, E.V. Shkarupeta, I.A. Purgaeva, R.V. Fedorenko, Transformation of positions, competences and skills in the digital economy industry. In: V. Mantulenko (Ed.), Proceedings of GCPMED 2018 - International Scientific Conference "Global Challenges and Prospects of the Modern Economic Development", The European Proceedings of Social \& Behavioural Sciences EpSBS, LVII (pp. 953-959). London: Future Academy (2019). DOI: 10.15405/epsbs.2019.03.94.

3. A.A. Polidi, Z.O. Goukasyan, I.A. Maslova, R.V. Fedorenko, Some aspects of the quality of corporate governance in digital economy. In: V. Mantulenko (Ed.), Proceedings of the $17^{\text {th }}$ International Scientific Conference "Problems of Enterprise Development: Theory and Practice” 2018. SHS Web of Conferences, 62, 04002 (2019). DOI: $10.1051 /$ shsconf/20196204002.

4. N.V. Molotkova, A.I. Popov, Organization of training of engineers for innovation. Alma mater: Bulletin of High School, 4, 9-14 (2019). DOI:10.20339/AM.04-19.009. [in Rus.].

5. S. Marathe, Digitalization in education sector. International Journal of Trend in Scientific Research and Development (IJTSRD), Special Issue: International Conference on Digital Economy and its Impact on Business and Industry, 51-56 (2018). DOI: 10.31142/ijtsrd18670.

6. M. Douse, P. Uys, TVET teaching in the time of digitization. In S. McGrath, M. Mulder, J. Papier, R. Suart (Eds.), Handbook of Vocational Education and Training (pp. 1-16). Cham: Springer (2019). DOI: 10.1007/978-3-319-49789-1 75-1.

7. J. Böhner, M. Scholz, J. Franke, A. Sauer, Integrating digitization technologies into resource efficiency driven industrial learning environments. Procedia Manufacturing, 23, 39-44 (2018). DOI: 10.1016/j.promfg.2018.03.158.

8. F. Li, J. Yang, J. Wang, Sh. Li, L. Zheng, Integration of digitization trends in learning factories. Procedia Manufacturing, 31, 343-348 (2019). DOI: 10.1016/j.promfg.2019.03.054.

9. A.I. Popov, A.D. Obukhov, Conceptual approaches to automated management of professional education. Transactions of the Tambov State Technical University, 24(2), 246-257 (2018). DOI: 10.17277/vestnik.2018.02.pp.246-257. [in Rus.]. 